\title{
Correlation of Suicidal Thoughts and Toxoplasmosis in Patients With Depression
}

\author{
Ilkay Bahceci $^{1}$, Bulent Bahceci ${ }^{2}$, Senol Senturk ${ }^{3}$, Ilknur E. Yildiz ${ }^{4}$, Zihni A. Yazici ${ }^{1}$ \\ 1. Medical Microbiology, Recep Tayyip Erdoğan University, Medical Faculty, Rize, TUR 2. Psychiatry, Recep Tayyip \\ Erdoğan University, Medical Faculty, Rize, TUR 3. Gynecology and Obstetrics, Recep Tayyip Erdoğan University, \\ Medical Faculty, Rize, TUR 4. Infectious Diseases, Recep Tayyip Erdoğan University, Medical Faculty, Rize, TUR
}

Corresponding author: Ilkay Bahceci, mdilkaybahceci@gmail.com

\section{Abstract \\ Objective}

We investigated the correlation between serum anti- Toxplasma gondii IgG and suicidal thoughts in depressive patients.

\section{Methods}

Depressive patients with $(\mathrm{n}=100)$ and without $(\mathrm{n}=100)$ suicidal thoughts along with 100 healthy control subjects were recruited for this study. In all three groups, a semi-structured clinical interview form called Structured Clinical Interview for DSM-IV (Diagnostic and Statistical Manual of Mental Disorders) Axis-I Disorder (SCID-I), Hamilton Depression Rating Scale (HAMD), suicidal behavior scale, and a sociodemographic data form were completed. Sera from all participants were taken, and anti-toxoplasma IgG was measured by Enzyme Linked Immunosorbent Assay (ELISA)-Chemiluminescent Microparticle Immunoassay. Statistical analysis of the data was performed.

\section{Results}

The serum anti-toxoplasma IgG levels of patients with suicidal thoughts were significantly higher than those without suicidal thoughts and the controls, which were $80.04 \pm 40.66,78 \pm 14.82$, and $19.98 \pm 14.65$, respectively, $\mathrm{p}<0.001$. There was no correlation between toxoplasma IgG and HAMD score in patients lacking suicidal thoughts $(\mathrm{r}=-0.112, \mathrm{p}=0.463)$.

\section{Conclusion}

This study shows a correlation between seropositivity for anti-Toxoplasma gondii IgG and depression with suicidal thoughts.

Review began 01/30/2021 Review ended 02/03/2021 Published 02/16/2021

\section{๑) Copyright 2021}

Bahceci et al. This is an open access article distributed under the terms of the Creative Commons Attribution License CC-BY 4.0., which permits unrestricted use, distribution, and reproduction in any medium, provided the original author and source are credited.
Categories: Psychiatry, Infectious Disease

Keywords: depression, depressive patients, anti-toxoplasma gondii igg, suicidal thoughts

\section{Introduction}

Toxoplasmosis and depression are close concepts in their stages in modern, isolated human life. Feline contact by humans is on the increase. In a report prepared by the World Health Organization (WHO) on World Mental Day (October 10, 2012), whose main theme was "Depression as a Global Crisis," depression accounted for $4.3 \%$ of the global illness burden and was the third leading cause of illness [1]. It has been reported that $20 \%$ of the emerging diseases due to psychiatric disorders in Europe are resulted from depression, and in some countries this rises up to $26 \%$. Lifetime risk for major depressive disorder was $5 \%$ $12 \%$ in men and $10 \%-25 \%$ in women, and the point prevalence in community samples of major depressive disorder in adults ranged from $5 \%-9 \%$ for women to $2 \%-3 \%$ for men. Depression is an important public health problem that causes 3000 deaths per day as a result of suicide. Longitudinal follow-up studies show that $10 \%-15 \%$ of suicide attempts have been successful [1,2].

Toxoplasma gondii is a zoonotic intracellular parasite that is reported to have infected approximately one third of the world population [3]. The sexual reproduction stage of this protozoan is carried out in the small intestinal epithelium of felines, and the excreted oocysts are taken by humans and other mammals coincidentally with water and food. Mammalian infections occur more often with the sporozoites that develop in the oocyst [4]. T. gondii oocysts that are resistant to gastric acid infect all cells in the digestive tract, then cross the blood-brain barrier (BBB), settle in astrocytes and neurons, and remain latent in the brain for a long time [5].

Even though the details of the mechanism of crossing the BBB are unclear, the parasite is known to localize in the orbitofrontal cortex, amygdala, hyppocampus, anterior cingulate cortex, and basal ganglion as 
revealed by neurological scanning for depression [6-8]. T. gondii can cause depressive behavioral changes such as nervousness and aggression, which are risk factors for suicide attempts by causing changes in host serotonergic systems [9-12]. In previous studies, although the relationship between toxoplasma seropositivity and suicide attempt was investigated in depressed patients, no study investigating the relationship between this parasite and suicidal ideation was found, which is the focus of this study.

\section{Materials And Methods}

Hundred depressive patients (aged 18-65 years) with suicidal ideation (group I), 100 depressed patients without suicidal ideation (group II), and 100 healthy control subjects (group III) were recruited for the study. The patients were selected from those who remotely consulted the hospital psychiatry outpatient clinic. Informed consent was obtained from all three groups. Exclusion criteria included pregnancy; psychiatric and any other drug treatment; endocrinological, metabolic, neurological, cardiologic, infectious disease; additional psychiatric comorbidity except for depression; and psychiatric disease in the control group. In all three groups, a semi-structured clinical interview form called Structured Clinical Interview for DSM-IV (Diagnostic and Statistical Manual of Mental Disorders) Axis-I Disorder (SCID-I) [13], a Hamilton Depression Rating Scale [14], a suicidal behavior scale [15], and a sociodemographic data form drawn by the investigators were completed for DSM-IV Axis-I diagnoses.

From the antecubital region of all participants, $2 \mathrm{ml}$ of venous blood was taken and centrifuged at $4000 \mathrm{rpm}$ for 10 minutes, and the serum was stored at $-20^{\circ} \mathrm{C}$. Sera from all participants were screened/titrated by an Enzyme Linked Immunosorbent Assay (ELISA) kit provided by Architect System, Abbott Diagnostics, Germany, in accordance with the criteria of macro-ELISA and chitin evaluation as per recommendation of the manufacturer. Anti-toxo IgG values that ranged from zero to 1.6 were considered non-reactive, while those with values greater than 1.6 were considered reactive. Ethical approval was obtained from the Medical School Clinical Studies Ethics Committee (Decision No: 2014/130).

\section{Statistical evaluation}

Statistical analysis was performed using the Statistical Package for Social Sciences (SPSS) version 18.0 (IBM Corp., Armonk, NY). Normal distribution of continuous variables was tested with Kolmogorov-Smirnov test. Chi-square test was used for categorical variables, and student's t-test was used for continuous variables. Correlation analysis was performed by the Spearman correlation test. One-way ANOVA with Dunnett's posthoc test was used. The level of significance was set as $\mathrm{p}<0.05$.

\section{Results}

There were no significant differences among the groups for gender distribution $(\mathrm{p}=0.105)$ and mean age $(\mathrm{p}$ $=0.107)$ (Table 1 ). Hamilton depression scores, the presence of anti-toxoplasma IgG, and the IgG levels of the groups are shown in Table 1. 


\section{Cureus}

\begin{tabular}{|c|c|c|c|c|c|}
\hline \multicolumn{2}{|l|}{ Parameters } & Group I & Group II & Group III & $p$ Value \\
\hline \multicolumn{6}{|l|}{ Gender } \\
\hline Female & $n(\%)$ & 65 (65) & $68(68)$ & 61 (61\%) & \multirow{2}{*}{$0.105^{\mathrm{a}}$} \\
\hline Male & $\mathrm{n}(\%)$ & 35 (35) & 32 (32) & 39 (39\%) & \\
\hline Age & Mean \pm SD & $30.14 \pm 7.29$ & $31.94 \pm 8.19$ & $29.73 \pm 8.43$ & $0.107^{b}$ \\
\hline \multicolumn{6}{|l|}{ Toxo IgG } \\
\hline Positive (n) & $n(\%)$ & 37 (37) & 35 (35) & $21(21)$ & \multirow{2}{*}{$<0.001^{2}$} \\
\hline Negative (n) & n (\%) & $63(63)$ & $65(65)$ & 79 (79) & \\
\hline \multirow{3}{*}{ HAMD } & Mean \pm SD & $23.14 \pm 6.24$ & $20.90 \pm 3.34$ & & $<0.001^{\mathrm{C}}$ \\
\hline & Mean \pm SD & $23.14 \pm 6.24$ & & $3.76 \pm 1.61$ & $<0.001^{\mathrm{C}}$ \\
\hline & Mean \pm SD & & $20.90 \pm 3.34$ & $3.76 \pm 1.61$ & $<0.001^{\mathrm{C}}$ \\
\hline Toxo IgG level & Mean \pm SD & $80.04 \pm 40.66$ & $36.78 \pm 14.82$ & $19.98 \pm 14.65$ & $<0.001^{\mathrm{c}}$ \\
\hline
\end{tabular}

TABLE 1: Data for depressive patients with (I) and without (II) suicidal ideation and healthy control (III) groups

Group I: depressive patients with suicidal ideation, group II: depressive patients without suicide ideation, group III: healthy control.

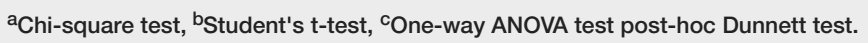

SD: Standard deviation; HAMD: Hamilton Depression Rating Scale.

$p<0.05$ : Statistically significant.

While there was a significant correlation between the HAMD scores and IgG values for group I ( $r=0.650 ; p<$ $0.001)$, this was not the case for group II $(r=-0.112 ; p=0.463)$. No correlation was found between these two groups in terms of age and gender (Table 2).

\begin{tabular}{|c|c|c|c|c|}
\hline \multirow[t]{2}{*}{ IgG } & \multicolumn{2}{|c|}{ Group I } & \multicolumn{2}{|c|}{ Group II } \\
\hline & $r$ & $\mathrm{p}$ & $r$ & $p$ \\
\hline HAMD & 0.65 & $<0.001$ & -0112 & 0.463 \\
\hline Age & 0.005 & 0.966 & 0.137 & 0.103 \\
\hline Gender & 0.187 & 0.126 & -0.129 & 0.399 \\
\hline
\end{tabular}

\section{TABLE 2: Correlation of HAMD scores and IgG values}

Spearman correlation test, $\mathrm{p}<0.05$.

HAMD: Hamilton Depression Rating Scale.

\section{Discussion}

Our study differs from previous studies in terms of investigating the relationship between suicide and $T$. gondii IgG seropositivity. Incorporation of depressive patients who did not attempt suicide in the study but had suicidal ideation during the study accounts for this difference. There has been no other study utilizing a similar methodology to study the relationship between HAMD scores and suicidal ideation in the literature.

In recent years, rapidly increasing suicide rates proved to be an important health problem for many 
countries, including Turkey. Therefore, clinicians must be aware of the assessment methods of the risk factors to enable them to take preventive/deterring measures [16,17]. For this reason, a test that can be easily accessed, cheap, fast, and accurate can be drawn by investigators for predicting possible suicide.

Seropositivity for T. gondii IgG varies worldwide and ranges between $15 \%$ and $87 \%$ [18]. In Turkey, this rate was found to be $23.1 \%$, which is similar to our findings (21\%) for group III [19]. Seropositivity for T. gondii IgG was found to be between $13 \%$ and $41 \%$ in previous studies in depressive patients [3,20,21]. In this study, this positivity was $37 \%$ and $35 \%$ for depressive patient groups I and II, both with and without suicidal ideation, respectively. These differences in studies are thought to be related to factors such as nutritional habits, severity of climate, and pet care.

The relationship between seropositivity for T. gondii IgG and suicide attempt has been investigated. The seropositivity rates of individuals who attempted suicide were found to be higher than those of the control group [19,20,22-25]. Unlike these studies and our study, Alvarado-Esquivel et al. found no relationship between T. gondii IgG seropositivity and suicide [26].

However, this study shows that there is a strong correlation between the HAMD scores of depressive patients who are suicidal and contemplating suicide. No correlation was found between the HAMD scores of depressive patients without suicidal thoughts and the suicidal ideation group. In addition, IgG levels in patients with and without suicidal ideation were statistically significantly different and higher in patients with suicidal ideation. These results suggest that $T$. gondii Ig G levels may be important in predicting suicide, an important public health problem, and that our research will be the precursor to further work.

The limitations of this study include low subject numbers and confinement in the same geographic region.

\section{Conclusions}

This study differs from previous studies in terms of investigating the relationship between suicide and $T$. gondii IgG seropositivity. Incorporation of depressive patients who did not attempt suicide in the study but had suicidal ideation during the study accounts for this difference. There has been no other study utilizing a similar methodology to study the relationship between HAMD scores and suicidal ideation in the literature. The data shows that the seropositivity of $T$. gondii IgG in depressive patients with or without suicidal ideation is higher than the healthy control and that it is even higher in patients with suicidal ideation than those without.

\section{Additional Information \\ Disclosures}

Human subjects: Consent was obtained or waived by all participants in this study. Rize University Medical School Clinical Studies Ethics Committee issued approval 2014/130. Ethical approval was obtained from the Medical School Clinical Studies Ethics Committee (Decision No: 2014/130). Animal subjects: All authors have confirmed that this study did not involve animal subjects or tissue. Conflicts of interest: In compliance with the ICMJE uniform disclosure form, all authors declare the following: Payment/services info: All authors have declared that no financial support was received from any organization for the submitted work. Financial relationships: All authors have declared that they have no financial relationships at present or within the previous three years with any organizations that might have an interest in the submitted work. Other relationships: All authors have declared that there are no other relationships or activities that could appear to have influenced the submitted work.

\section{References}

1. World Federation For Mental Health (WFMH): Depression: A Global Crisis. World Mental Health Day, October 10 2012. 2012.

2. Cullberg J, Wasserman D, Stefansson CG: Who commits suicide after a suicide attempt? An 8 to 10 year follow up in a suburban catchment area. Acta Psychiatr Scand. 1988, 77:598-603. 10.1111/j.16000447.1988.tb05173.x

3. Pearce BD, Kruszon-Moran D, Jones JL: The relationship between Toxoplasma gondii infection and mood disorders in the third national health and nutrition survey. Biol Psychiatry. 2012, 72:290-5. 10.1016/j.biopsych.2012.01.003

4. Gotteland C, Gilot-Fromont E, Aubert D, et al.: Spatial distribution of Toxoplasma gondii oocysts in soil in a rural area: influence of cats and land use. Vet Parasitol. 2014, 205:629-637. 10.1016/j.vetpar.2014.08.003

5. Carruthers VB, Suzuki Y: Effects of Toxoplasma gondii infection on the brain . Schizophr Bull. 2007, 33:74551. 10.1093/schbul/sbm008

6. Steffens DC, McQuoid DR, Welsh-Bohmer KA, Krishnan KR: Left orbital frontal cortex volume and performance on the benton visual retention test in older depressives and controls. Neuropsychopharmacology. 2003, 28:2179-83. 10.1038/sj.npp.1300285

7. Feustel SM, Meissner M, Liesenfeld O: Toxoplasma gondii and the blood-brain barrier . Virulence. 2012, 3:182-92. 10.4161/viru.19004

8. Burke J, McQuoid DR, Payne ME, Steffens DC, Krishnan RR, Taylor WD: Amygdala volume in late-life depression: relationship with age of onset. Am J Geriatr Psychiatry. 2011, 19:771-6. 
10.1097/JGP.0b013e318211069a

9. Mann JJ: Neurobıology of suicidal behaviour. Nat Rev Neurosci. 2003, 4:819-28. 10.1038/nrn1220

10. Flegr J: Effects of toxoplasma on human behavior. Schizophr Bull. 2007, 33:757-60. 10.1093/schbul/sbl074

11. Cook TB, Brenner LA, Cloninger CR et al.: "Latent" infection with Toxoplasma gondii: association with trait aggression and impulsivity in healthy adults. J Psychiatr Res. 2015, 60:87-94.

10.1016/j.jpsychires.2014.09.019

12. Webster JP: Rats, cats, people and parasites: the impact of latent toxoplasmosis on behaviour . Microbes Infect. 2001, 3:1037-45. 10.1016/s1286-4579(01)01459-9

13. First MB, Spitzer RL, Gibbon M, Williams JBW: Structured clinical interview for DSM-IV axis I disorders, clinician version (SCID-CV). American Psychiatric Press, Washington, DC; 1996.

14. Hamilton M: A rating scale for depression. J Neurol Neurosurg Psychiatry. 1960, 23:56-62. 10.1136/jnnp.23.1.56

15. Linehan M, Nielsen S: Assessment of suicide ideation and parasuicide: hopelessness and social desirability . J Consult Clin Psychol. 1981, 49:773-75. 10.1037/0022-006X.49.5.773

16. Baker SP, Hu G, Wilcox HC, Baker TD: Increase in suicide by hanging/suffocation in the U.S., 2000-2010 . Am J Prev Med. 2013, 44:146-9. 10.1016/j.amepre.2012.10.010

17. Özgüven HD: İntihar Davranışının Epidemiyolojisi. Türkiye Klinikleri Psikiyatri Özel Dergisi. 2008, 1:1-7.

18. Özcel MA: Özcel'in Tıbbi parazit hastalıkları. Gürüz AY, Özcel MA Toxoplasmosis. Türkiye Parazitoloji Derneği Yayını İzmir. 2007, 22:141-189.

19. Lester D: Brain parasites and suicide. Psychol Rep. 2010, 107:424. 10.2466/12.13.PR0.107.5.424

20. Yagmur F, Yazar S, Temel HO, Cavusoglu M: May Toxoplasma gondii increase suicide attempt-preliminary results in Turkish subjects?. Forensic Sci Int. 2010, 199:15-7. 10.1016/j.forsciint.2010.02.020

21. Groër MW, Yolken RH, Xiao JC, et al.: Prenatal depression and anxiety in Toxoplasma gondii-positive women. Am J Obstet Gynecol. 2011, 204:433-1. 10.1016/j.ajog.2011.01.004

22. Arling TA, Yolken RH, Lapidus M, et al.: Toxoplasma gondii antibody titers and history of suicide attempts in patients with recurrent mood disorders. J Nerv Ment Dis. 2009, 197:905-8. 10.1097/NMD.0b013e3181c29a23

23. Zhang Y, Träskman-Bendz L, Janelidze S, et al.: Toxoplasma gondii immunoglobulin $\mathrm{G}$ antibodies and nonfatal suicidal self-directed violence. J Clin Psychiatry. 2012, 73:1069-76. 10.4088/JCP.11m07532

24. Cetinkaya Z, Yazar S, Gecici O, Namli MN: Anti-Toxoplasma gondii antibodies in patients with schizophrenia - preliminary findings in a Turkish sample. Schizophr Bull. 2007, 33:789-91. 10.1093/schbul/sbm021

25. Ling VI, Lester D, Mortensen PB, Langenberg PW, Postolache TT: Toxoplasma gondii seropositivity and suicide rates in women. J Nerv Ment Dis. 2011, 199:440-4. 10.1097/NMD.0b013e318221416e

26. Alvarado-Esquivel C, Sánchez-Anguiano LF, Arnaud-Gil CA, et al.: Toxoplasma gondii infection and suicide attempts: a case-control study in psychiatric outpatients. J Nerv Ment Dis. 2013, 201:948-52. 10.1097/NMD.0000000000000037 